Article

\title{
Do Female Employees at Small and Medium Enterprises Perceive Open Source Software Usefulness and Satisfaction Differently from Male Employees? A Survey Analysis
}

\author{
Sanghyun Kim * and Hyunsun Park \\ School of Bus Admin, Kyungpook National University, Daegu 41566, Korea; sunny09@knu.ac.kr \\ * Correspondence: ksh@knu.ac.kr; Tel.: +82-53-950-5877
}

Received: 19 August 2018; Accepted: 25 September 2018; Published: 29 September 2018

check for updates

\begin{abstract}
Many companies, particularly small and medium enterprises (SMEs), use open source software (OSS) to promote the strategic application of their information technology assets. Several studies have claimed that male and female employees in SMEs differ in their use of various information technologies. This study investigates the factors influencing the perceived usefulness of and satisfaction with OSS among employees at SMEs in various industries, specifically comparing male and female employee perceptions. For this purpose, this study uses a proposed research model to examine the effects of quality factors-such as ease of maintenance, cost advantage, customization, and job relevance - on perceived usefulness of and satisfaction with OSS. Data were collected from 328 randomly selected survey responses of employees in various organizations using OSS. A structural equational model was created using AMOS 22.0 to test the proposed hypotheses in the research model. Results show that all OSS quality factors were significantly related to the perceived usefulness of OSS in both genders, positively affecting satisfaction. Moreover, the perceptions of male and female employees differed in relation to each research model variable. These findings suggest that employees value specific OSS qualities while perceiving its usefulness and their satisfaction.
\end{abstract}

Keywords: open source software; software quality; perceived usefulness; satisfaction; SMEs; gender

\section{Introduction}

The software market is rapidly changing, the industry gaining increasing importance and competitive advantage as it secures global recognition. Software firms play a crucial role in the creation, practical use, and spread of knowledge for businesses in the economic sphere (Chiasson and Lovato 2001). In addition, the software industry is one of the key players in the creation of new opportunities through its convergence with traditional industries such as automobile manufacturing, shipbuilding, and energy. For this reason, companies are demanding the development of rapid, low-cost, and highly efficient software, and interest in open source software (OSS) is rapidly increasing.

Unlike commercial software, where distributors or developers charge for services-including programming, training, and technical support-OSS involves the releasing of source code to the public without changing a fee. Sarrab and Rehman (2014) have claimed that any OSS is free to use and modify, and that source code can be redistributed free of charge. In addition, Marsan et al. (2012) have suggested that OSS can be defined as software whose source code is freely available to the public and can be used, copied, and distributed with or without modifications. As such, OSS differs from commercial software in terms of revenue generation-since a commercial software firm will not release source code and prohibits its modification, duplication, and distribution without 
due legal process. In addition to being free, OSS provides users with various benefits, such as easier software maintenance, reduced costs, and customization. These advantages make efficient development possible for user information systems. OSS is also significant in that it is produced through voluntary participation and contributions. For this reason, an increasing number of both individuals and firms are utilizing OSS for various purposes in a stable and cost-effective manner. Indeed, Nagy et al. (2010) have argued that the numerous benefits of OSS have led to the transitioning of organizations' software strategies away from the use of commercial software and toward OSS.

Despite these developments, however, there is a lack of research on user behavior and OSS usage. The majority of extant studies have limited their attention to the initial acceptance behavior of companies or general users (Gallego et al. 2008; Gwebu and Wang 2011; Van Loon and Toshkov 2015; Marsan et al. 2012; Mount and Fernandes 2013; Sarrab and Rehman 2014). These studies have primarily focused on how user characteristics - such as intrinsic and extrinsic motivation, innovation, and professionalism - affect user behavior. In addition to studies on the acceptance of OSS, research has been conducted on OSS success factors based on the information systems success model (Midha and Palvia 2012; Sarrab and Rehman 2014). These studies have concentrated on the benefits of OSS and users' intention to use it in terms of systems, services, and information quality. However, there are few empirical studies on OSS usefulness and satisfaction that focus on OSS quality factors (Kim and Song 2010). For an information system to be recognized as a continuously useful piece of technology in the market, it is necessary to understand users' perceptions and levels of satisfaction. Moreover, there has been little research undertaken on gender differences in user behavior related to OSS. Given this context, it is likely that empirical research on the perceived usefulness of OSS and user satisfaction within SMEs will improve our understanding of the effects of OSS. As such, this study seeks empirical answers to the following three research questions:

RQ 1: Do OSS quality factors positively affect the perceived usefulness of OSS?

RQ 2: Is the relationship between perceived usefulness and satisfaction still valid in OSS?

RQ 3: Do gender differences exist for each path of the proposed research model?

To answer these questions, this study developed a research model based on an information system success model (DeLone and McLean 2003) and an expectation confirmation model (Bhattacherjee 2001). Based on the relevant research, this research model includes four OSS quality factors-ease of maintenance, cost advantage, customization, and job relevance-to explain their causal relationships with perceived usefulness and satisfaction. To test gender differences, gender was proposed as a moderating effect. The verification of each path proposed in the research model was expected to improve our understanding of the behavior of individual or organizational OSS users.

\section{Literature Review, Proposed Research Model, and Hypotheses}

Information systems are adopted by organizations in order to improve the effectiveness of the whole organization by supporting the decision-making and work efficiency of its members. In other words, information systems affect organizational performance. According to the information system success model (DeLone and McLean 2003), the various quality factors-information, system, and service - of an information system increase the intention of users to utilize the system, as well as their levels of satisfaction. The model further claims that an increase in satisfaction positively affects individual and organizational performance. In explaining the success of the information system, these three quality factors have been studied in numerous contexts, such as in the adoption of smartphones (Cho 2012) and in cloud computing (Park and Jeong 2012). As such, quality factors and satisfaction have been used as representative variables to measure the performance of an information system. In addition, the expectation confirmation model claims that when employees have a positive perception of the usefulness of a specific information technology, their levels of satisfaction also increase. 
Studies on OSS have reported that individual factors (identification, innovativeness, and experience), technological factors (complexity, compatibility, cost, and usefulness), and organizational and environmental factors (competence and competitive pressure) have a significantly positive impact on individual behavior in terms of technology use (Van Loon and Toshkov 2015; Marsan et al. 2012; Mount and Fernandes 2013). Others (e.g., Chauhan et al. 2018) have focused on the determinants influencing the organizational adoption of OSS applications. Most of these studies selected the adoption of OSS as a dependent variable and only considered the intention to adopt OSS. Consequently, these studies have been limited insofar as they failed to address performance measurements such as the satisfaction with and usefulness of the technology.

Another issue in the social sciences associated with technology use is the digital divide between those who are competent in its use and those who are less so. The digital divide is contingent upon gender, age, education level, and income, and implies a difference in access to, as well as use and perception of, new information technology (Rice and Katz 2003). This situation has led to debate on how to secure universal access to the new digital culture in order to alleviate the social, political, and economic inequalities resulting from the rapid development of information and communications technology (McCreadie and Rice 1999). Among the various elements of the digital divide, the importance of gender has been emphasized in relation to the use of information technology in organizations. Despite the importance of gender in understanding employee behavior with respect to information technology, however, extant studies provide limited data on the differences in perception between men and women with regard to the use of information technology-including OSS, which is frequently used in SMEs. Overcoming the limitations of previous studies thus requires the investigation and assessment of both OSS performance measurements—such as satisfaction within organizations using OSS - and gender differences (Midha and Palvia 2012).

Figure 1 illustrates the proposed research model with the hypotheses this study empirically tests. The research model developed for this study introduces OSS quality factors for user analysis in relation to the perceived usefulness of and satisfaction with OSS. Sarrab and Rehman (2014) have proposed new quality characteristics for OSS usage based on the information system success model developed by DeLone and McLean (2003). They suggest that quality factors such as availability, reliability, reusability, and developer skills are important aspects of satisfying OSS users. However, Kim and Song (2010) have claimed that previous research on user behavior of information technology has shown that factors related to information, system, and service have significant influence on the usefulness of and satisfaction with specific information technology. They further emphasize that factors related to software quality-including its maintenance and cost benefits-should be examined in order to explain user satisfaction, particularly in exploring user behavior in relation to OSS. Moreover, Jusoh et al. (2012) have argued that factors such as maintenance, economic aspect, relative cost advantages, customization, and work-related software should be considered when evaluating user behavior.

In addition, Seddon et al. (1999) have demonstrated the importance of using different scales when adopting the information system success model in varying situations to reflect an understanding of the different interests involved and their relationships. Therefore, the proposed research model incorporates OSS quality factors to explain user behavior regarding perceived usefulness and satisfaction. Based on the relevant literature (e.g., Kim and Song 2010; Jusoh et al. 2012), this study proposes four OSS quality factors-namely, ease of maintenance, cost advantage, customization, and job relevance-as determinants of perception of OSS usefulness and satisfaction. This study also includes gender as a moderating variable to test whether the effects of OSS quality factors on the perceived usefulness and satisfaction of users differ according to gender. 


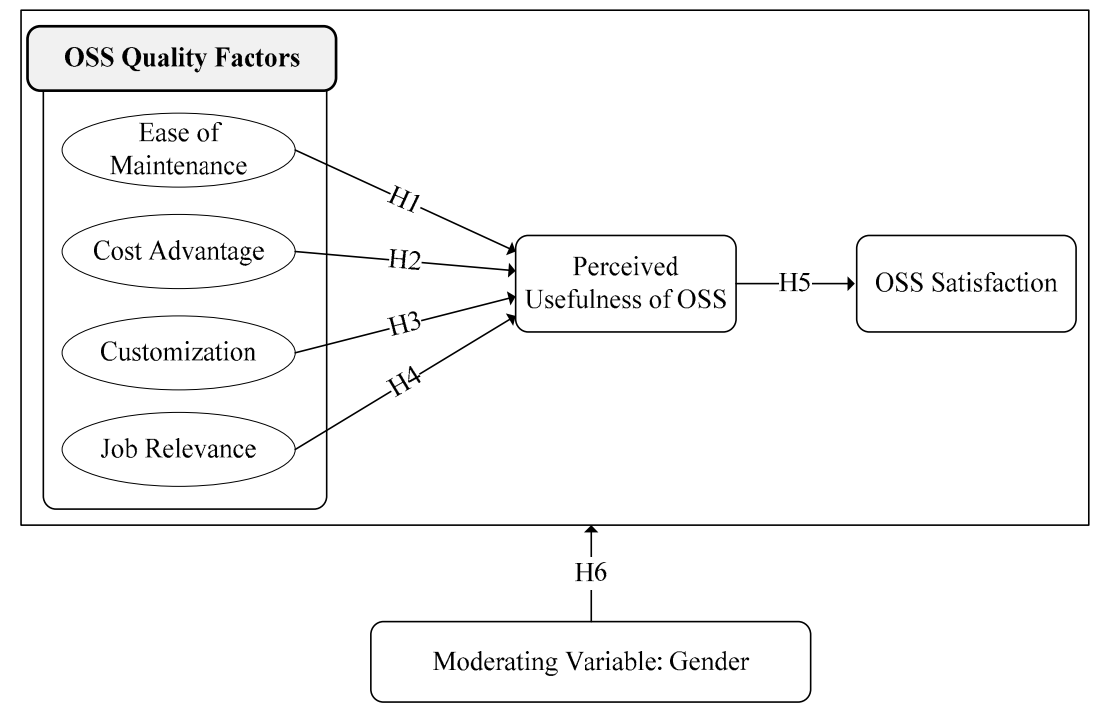

Figure 1. Research model with hypotheses.

\subsection{Ease of Maintenance}

Ease of maintenance is defined as the degree to which a person believes that maintaining and using OSS will be free of effort (Kim 2008). Davis (1989) found that perceived ease of use was a major driver of behavioral intentions and the actual behavior of an individual. Perceived ease of use has also been shown to have a direct impact on perceived usefulness (Venkatesh and Davis 2000). In other words, an information technology system will be recognized as useful if it is easy to use and maintain. Research measuring the application of information systems has suggested that perceived ease of use is an essential factor in user satisfaction (Bailey and Pearson 1983; Sarrab and Rehman 2014). This suggests that OSS will be used more often if less effort is required to use and maintain it, eventually resulting in improved job performance. Bailey and Bailey and Pearson (1983) have thus proposed ease of use and maintenance of information systems as major software quality factors, demonstrating that these factors had a significant impact on perceived usefulness. Based on these arguments, the following hypothesis is proposed:

Hypothesis 1 (H1). Ease of maintenance is positively associated with the perceived usefulness of OSS.

\subsection{Cost Advantage}

This study defines cost advantage as the degree to which employees believe that OSS use has monetary and non-monetary benefits, including the time and effort saved by using OSS. OSS users can freely access the system software regardless of any associated costs. This has resulted in growing interest from industry on to how to utilize OSS effectively. Indeed, information technology can incur prohibitive costs for companies with limited financial resources (Roger 1995). In general, the costs associated with information technology have always been a primary consideration in technology adoption (Chauhan et al. 2018; Kim 2008). These costs include various factors-such as the time and effort involved, as well as monetary considerations-and cannot be ignored in the process of software diffusion (Ven and Verelst 2011). In this regard, the biggest difference between OSS and commercial software concerns licensing costs (Lundell et al. 2010). In other words, OSS has a significant cost advantage because there is no license fee at all. Lower licensing costs have become an important reason for using OSS, and companies using OSS can save costs. Therefore, this study proposes the following hypothesis:

Hypothesis 2 (H2). Cost advantage is positively associated with the perceived usefulness of OSS. 


\subsection{Customization}

Customization is defined as the extent to which OSS is well designed, able to accommodate user needs, and attract user interest (Sarrab and Rehman 2014). Zeithaml et al. (2002) have argued that customization or personalization should be considered important in developing e-service quality because these aspects can enhance the efficiency and effectiveness of an information system. Van Riel et al. (2004) have suggested that usefulness is related to the individual's application of appropriate technology in terms of content and usage. Indeed, the software industry has been surprised by positive assessments of users regarding their expected OSS requirements (Sarrab and Rehman 2014). Thus, it appears that customizing OSS qualities to user needs will positively impact its perceived usefulness. Therefore, this study proposes the following hypothesis:

Hypothesis 3 (H3). Customization is positively associated with the perceived usefulness of OSS.

\subsection{Job Relevance}

This study defines job relevance as the extent to which OSS is needed at work and its relevance to that work (Kim 2008; Venkatesh and Davis 2000). According to the extended technology acceptance model, the usefulness of an information system is determined by an individual's perception of the degree to which the target system is applicable (Dishaw and Strong 1999). Venkatesh and Davis (2000) have demonstrated that job relevance has a positive effect on perceived usefulness. That is, if OSS can enhance job performance, the user will recognize the system as helpful. It is important to note that while individuals have different knowledge requirements, they still need to apply that knowledge in their jobs by using information systems (Chauhan et al. 2018). As such, the capacity of an information system to support an individual's job is likely to be significant. This study considered that a user was more likely to appreciate the benefits of OSS if the OSS was highly relevant to their job. Therefore, the following hypothesis is proposed:

Hypothesis 4 (H4). Job relevance is positively associated with the perceived usefulness of OSS.

\subsection{Perceived Usefulness and Satisfaction}

In this study, the perceived usefulness of OSS is defined as the extent to which an individual believes that using OSS will improve their performance (Bhattacherjee 2001; Davis 1989; Mount and Fernandes 2013). Satisfaction is defined as the extent to which users believe that the available OSS meets their information requirements (DeLone and McLean 2003; Sarrab and Rehman 2014). Davis (1989) has claimed that perceived usefulness is a critical factor in explaining user behavior: that is, that the beliefs of a user-which are formed through perceived usefulness-have a crucial influence on a user's adoption of and use intentions for an information system. Previous studies have shown that perceived usefulness directly influences user satisfaction (Seddon and Kiew 1996; Wang and Song 2017). Seddon (1997) has demonstrated that satisfaction constitutes a user's subjective evaluation of an information system based on its quality. In addition, users are more likely to evaluate an information system positively if they perceive the system as useful. As such, perceived usefulness has been advanced as a variable that consistently affects subsequent user expectations and behavior concerning information systems (Bhattacherjee 2001; Kim 2008). Therefore, this study considers that the perceived usefulness of OSS has a positive effect on OSS satisfaction and proposes the following hypothesis:

Hypothesis 5 (H5). The perceived usefulness of OSS is positively associated with OSS satisfaction. 


\subsection{The Moderating Effect of Gender}

Extant research on user behavior in relation to specific information technology according to gender has been conducted in various ways. For example, Ong and Lai (2006) have investigated the effect of gender in the electronic learning (e-learning) context by focusing on the effect of various factors related to user convenience. In doing so, they found that men rated computer self-efficacy, perceived usefulness, perceived ease of use, and behavioral intention to use e-learning higher than women. In addition, An and Kim (2011) have examined the gender gap in the context of mobile commerce. They found that the relative influence of predicting variables on mobile commerce acceptance differed significantly between male and female users-particularly in regard to the impact of perceived risk, perceived usefulness, and subjective norms on the acceptance of mobile commerce among male and female respondents. Female customers were found to be more concerned with the safety of mobile commerce compared with male customers, while the perception of usability significantly influenced the acceptance intentions of male customers.

Meanwhile, Rhee (2010) has investigated the impact of e-customer relationship management (CRM) activities on customer satisfaction and repurchase intentions, finding that male customers were often satisfied simply by receiving reliable service from a company. However, continuous management-such as providing discount events or event information and issuing discount coupons-affected female consumer satisfaction and repurchase intentions, indicating a significant difference between male and female customer behavior. On the basis of these studies, this study expects that male and female employees will have different perceptions of and behavior regarding OSS. To validate this claim, the following hypotheses are proposed:

Hypothesis 6 (H6). There is a significant difference in the relationship between OSS quality factors and the perceived usefulness of OSS according to gender.

Hypothesis 7 (H7). There is a significant difference in the relationship between the perceived usefulness of OSS and OSS satisfaction according to gender.

\section{Materials and Methods}

\section{Data Collection}

Data were collected from employees in organizations currently using OSS as a part of their information technology. A total of 1000 employees from 10 organizations (two manufacturing, four IT, two retail, one service, and one undefined/other) were surveyed. A total of 339 responses were collected over five months. However, 11 responses were discarded because they were incomplete; therefore, a total of 328 valid responses were used in this analysis. The final response rate was $32.8 \%$. The largest number of responses came from employees in the IT industry with 134 responses $(40.85 \%)$, followed by the retail $(69,21.04 \%)$ and manufacturing $(68,20.73 \%)$ industries. Seven responses in the "other" industry category consisted of three responses from employees in logistics and transportation, two responses from finance, and two responses from media/art. These results suggest that OSS is used in many industries.

Of the participating employees, $53.66 \%$ were male and $46.34 \%$ were female. In terms of the positions of the respondents, $28.5 \%$ were chief information officers (CIOs) responsible for information systems, followed by chief executive officers (CEOs) and senior managers comprising $24.39 \%$ and $24.09 \%$, respectively. Most responses were from management positions, increasing data validity. A total of $91.16 \%$ of respondents indicated that they use web applications, $83.54 \%$ indicated that they use databases, and $62.50 \%$ indicated that they use operating systems. The majority of respondents $(89.33 \%$ ) had been using OSS for various business purposes for more than three years. Table 1 provides a profile of the respondents. 
Table 1. Breakdown of the study participants $(n=328)$.

\begin{tabular}{cccc}
\hline & Demographic Categories & Range & Percentage \\
\hline \multirow{3}{*}{ Industry } & Manufacturing & 68 & $20.73 \%$ \\
& IT & 134 & $40.85 \%$ \\
& Retail & 69 & $21.04 \%$ \\
& Service & 50 & $15.24 \%$ \\
Gender & Other & 7 & $2.13 \%$ \\
\hline \multirow{3}{*}{ Position } & Male & 176 & $53.66 \%$ \\
& Female & 152 & $46.34 \%$ \\
\hline \multirow{3}{*}{ Type of open source software (OSS) } & Chief Executive Officer (CEO) & 80 & $24.39 \%$ \\
(multiple responses) & Chief Information Officer (CIO) & 92 & $28.05 \%$ \\
& Senior Manager & 79 & $24.09 \%$ \\
& Director & 54 & $16.46 \%$ \\
& Others & 23 & $7.01 \%$ \\
\hline & OS & 205 & $62.50 \%$ \\
& Database & 274 & $83.54 \%$ \\
& Web Application & 299 & $91.16 \%$ \\
Length of Time Using OSS & Other & 54 & $16.46 \%$ \\
\hline & $<2$ years & 35 & $10.67 \%$ \\
& $<3$ years & 101 & $30.79 \%$ \\
& $<4$ years & 116 & $35.37 \%$ \\
& $>5$ years & 76 & $23.17 \%$ \\
\hline
\end{tabular}

Of the items in the questionnaire were measured using a 7-point Likert scale, ranging from (1) "strongly disagree" to (7) "strongly agree." To verify the proposed research model, the survey items were first evaluated through interviews with domestic companies and employees interested in OSS. As shown in Appendix A, the finalized questionnaires were then evaluated based on a theoretical review. In addition, a pre-test was conducted in order to elaborate on and select the questions used to verify the validity of the items. The results of this verification showed that none of the questions interfered with item validity. Operational definitions and related studies for each variable are provided in Table 2.

Table 2. Constructs and related studies.

\begin{tabular}{ccc}
\hline Construct & Operational Definition & Related Studies \\
\hline Ease of Maintenance & $\begin{array}{c}\text { The degree to which a person believes } \\
\text { that maintaining and using an OSS will } \\
\text { be effortless. }\end{array}$ & Davis (1989) \\
Cost Advantage & $\begin{array}{c}\text { The degree to which employees believe } \\
\text { in the monetary and non-monetary } \\
\text { benefits of OSS, including the time and } \\
\text { effort saved by using OSS. }\end{array}$ & Son et al. (2005) \\
\hline Customization & $\begin{array}{c}\text { The extent to which OSS is well } \\
\text { designed to accommodate user needs } \\
\text { and attract their interest. }\end{array}$ & Sarrab and Rehman (2014) \\
\hline Job Relevance & $\begin{array}{c}\text { The extent of the need for OSS and its } \\
\text { relevance to work. }\end{array}$ & $\begin{array}{c}\text { Venkatesh and Davis (2000); } \\
\text { Perceived Usefulness of OSS }\end{array}$ \\
\hline OSS Satisfaction & $\begin{array}{c}\text { The extent to which an individual } \\
\text { believes that using OSS will improve } \\
\text { their performance. }\end{array}$ & Mount and Fernandes (2013) \\
\hline & $\begin{array}{c}\text { The extent to which users believe the } \\
\text { OSS available to them meets their } \\
\text { information requirements. }\end{array}$ & Sarrab and Rehman (2014) \\
\hline
\end{tabular}




\section{Results and Discussion}

\subsection{Assessment of the Measurement Model}

Prior to testing the research hypotheses, the measurement model's reliability and validity were verified. First, the overall fitness of the measurement model was confirmed, with several indices resulting from the confirmatory factor analysis (CFA) using AMOS 22.0. The results showed that two items-ease of maintenance (em) 4 and customization (cus) 3-had a cross-loading issue; therefore, these items were removed. The modified measurement model was then reexamined. The results showed a good fit, with all indices greater than the acceptable threshold. Table 3 summarizes the result of the overall fit test.

Table 3. Summary of the overall fit indices for the measurement model $(n=328)$.

\begin{tabular}{ccccccc}
\hline Model & NFI & GFI & AGFI & CFI & $\chi^{2} /$ df & RMSEA \\
\hline Measurement Model & 0.878 & 0.919 & 0.843 & 0.922 & 1.776 & 0.081 \\
Revised Model & 0.937 & 0.945 & 0.899 & 0.948 & 1.693 & 0.049 \\
Recommended value & $\geq 0.9$ & $\geq 0.9$ & $\geq 0.8$ & $\geq 0.9$ & $\leq 3.0$ & $\leq 0.10$
\end{tabular}

Note: In the revised model, em4 and cus3 were removed. Abbreviations: NFI, normed fit index; GFI, goodness-of-fit index; AGFI, adjusted goodness-of-fit index; CFI, comparative fit index; $\chi^{2} / \mathrm{df}, \chi^{2} /$ degree of freedom; RMSEA, root mean square error of approximation.

Next, reliability and validity were assessed using two validity tests (convergent and discriminant). Reliability was examined using Cronbach's alpha, which should be greater than 0.7 (Teo et al. 1999). As shown in Table 4, the alpha value for all latent constructs was greater than the recommended value in ranging from 0.763 to 0.921 . Thus, the reliability of the measurement model was confirmed as showing strong internal consistency.

Table 4. Results of reliability testing.

\begin{tabular}{cccc}
\hline Latent Construct & \# of Item & Removed Item & Cronbach's Alpha \\
\hline Ease of Maintenance & 4 & 1 & 0.837 \\
Cost Advantage & 4 & 0 & 0.899 \\
Customization & 4 & 1 & 0.763 \\
Job Relevance & 3 & 0 & 0.815 \\
Perceived Usefulness of OSS & 4 & 0 & 0.899 \\
OSS Satisfaction & 2 & 0 & 0.921 \\
\hline
\end{tabular}

A discriminant validity test was conducted to verify that items designed to measure a particular latent construct did not correlate with other constructs. The square root of the average variance extracted (AVE) and correlation values were used to test discriminant validity. The AVE square root value of each latent construct must be greater than the correlation value of species and transverses in order to ensure discriminant validity. As shown in Table 5, all values representing the square root of AVE for each latent construct were greater than the correlation values, demonstrating discriminant validity.

Indicating how closely the selected items are related to the latent construct being assessed, convergent validity was examined using CFA according to the factor loading value, as well as other indices such as composite reliability (CR) and average variance extracted (AVE). To achieve convergent validity, the factor loadings of each measurement item and the CR should be at least 0.7 and the AVE should be larger than 0.5 (Chin 1998). Table 6 shows the results of the convergent validity assessment. All items had factor loading greater than 0.7 , while the CR for all latent constructs ranged from 0.830 to 0.922 , and from 0.620 to 0.801 for the AVE. As such, convergent validity was ensured. 
Table 5. Results of convergent validity.

\begin{tabular}{|c|c|c|c|c|c|c|}
\hline Latent Construct & Item & Mean & SD & Factor Loading & CR & AVE \\
\hline \multirow{4}{*}{ Ease of Maintenance (em) } & em1 & 5.003 & 0.103 & 0.785 & \multirow{4}{*}{0.830} & \multirow{4}{*}{0.620} \\
\hline & em2 & 4.436 & 0.350 & 0.840 & & \\
\hline & em3 & 5.081 & 0.626 & 0.733 & & \\
\hline & em4 & & & oved & & \\
\hline \multirow{4}{*}{ Cost Advantage (ca) } & ca1 & 5.066 & 0.215 & 0.795 & \multirow{4}{*}{0.889} & \multirow{4}{*}{0.667} \\
\hline & $\mathrm{ca} 2$ & 4.607 & 0.534 & 0.870 & & \\
\hline & ca3 & 5.248 & 0.086 & 0.766 & & \\
\hline & ca4 & 5.043 & 0.416 & 0.832 & & \\
\hline \multirow{4}{*}{ Customization (cus) } & cus1 & 3.129 & 0.572 & 0.826 & \multirow{4}{*}{0.841} & \multirow{4}{*}{0.699} \\
\hline & cus2 & 4.640 & 0.195 & 0.757 & & \\
\hline & cus3 & & & ved & & \\
\hline & cus4 & 5.173 & 0.092 & 0.813 & & \\
\hline \multirow{3}{*}{ Job Relevance (jr) } & jr1 & 4.262 & 0.374 & 0.798 & \multirow{3}{*}{0.888} & \multirow{3}{*}{0.727} \\
\hline & jr2 & 5.106 & 0.736 & 0.866 & & \\
\hline & jr3 & 4.899 & 0.503 & 0.891 & & \\
\hline \multirow{4}{*}{ Perceived Usefulness of OSS (pu) } & pu1 & 4.254 & 0.685 & 0.786 & \multirow{4}{*}{0.922} & \multirow{4}{*}{0.748} \\
\hline & pu2 & 5.121 & 0.710 & 0.888 & & \\
\hline & pu3 & 4.788 & 0.208 & 0.894 & & \\
\hline & pu4 & 5.694 & 0.253 & 0.887 & & \\
\hline \multirow{2}{*}{ OSS Satisfaction (sat) } & sat1 & 5.680 & 0.501 & 0.912 & \multirow{2}{*}{0.890} & \multirow{2}{*}{0.801} \\
\hline & sat2 & 5.737 & 0.198 & 0.878 & & \\
\hline
\end{tabular}

Note: $\mathrm{SD}$, standard deviation; $\mathrm{CR}$, composite reliability; AVE, average variance extracted.

Table 6. Discriminant validity test.

\begin{tabular}{ccccccc}
\hline Latent Construct & $\mathbf{( 1 )}$ & $\mathbf{( 2 )}$ & $\mathbf{( 3 )}$ & $\mathbf{( 4 )}$ & $\mathbf{( 5 )}$ & $\mathbf{( 6 )}$ \\
\hline Ease of Maintenance & $\mathbf{0 . 7 8 7}$ & & & & & \\
Cost Advantage & 0.211 & $\mathbf{0 . 8 1 6}$ & & & & \\
Customization & 0.237 & 0.217 & $\mathbf{0 . 7 9 9}$ & & & \\
Job Relevance & 0.336 & 0.406 & 0.346 & $\mathbf{0 . 8 5 3}$ & & \\
Perceived Usefulness of OSS & 0.292 & 0.417 & 0.331 & 0.342 & $\mathbf{0 . 8 6 5}$ & \\
OSS Satisfaction & 0.425 & 0.411 & 0.366 & 0.366 & 0.483 & $\mathbf{0 . 8 9 6}$ \\
\hline
\end{tabular}

Note: The values in bold are the AVE (average variance extracted) square root values.

\subsection{The Structural Model Test}

The structural model was analyzed after the measurement model had been verified. The structural model was constructed using AMOS 22.0, through which the hypotheses could be verified. Structural model analysis allows for three important possibilities. First, it can provide information concerning how the data collected in this study fit with the structural model. Second, the degree of influence of each path of the research model can be measured by the standardized path coefficient $(\beta)$. Finally, it is possible to determine the explanatory power of the endogenous variables using the exogenous variables of the structural model through squared multiple correlation $\left(R^{2}\right)$.

After grouping the data by gender (male and female), the structural equation model was first performed on male data $(n=176)$. Following the overall fitness test of the structural model using male data, all indicators were above the recommended values stipulated by the literature to ensure fitness, as follows: $\chi^{2} /$ degree of freedom $\left(\chi^{2} / \mathrm{df}\right)=1.790$, normed fit index $(\mathrm{NFI})=0.944$, goodness-of-fit index $(\mathrm{GFI})=0.961$, adjusted goodness-of-fit index $(\mathrm{AGFI})=0.925$, comparative fit index $(C F I)=0.953$, and root mean square error of approximation $($ RMSEA $)=0.036$. Therefore, the male data 
fit the structural model well. The fitness test on female data also indicated a good fit: $\chi^{2} / \mathrm{df}=1.820$, $\mathrm{NFI}=0.929, \mathrm{GFI}=0.965, \mathrm{AGFI}=0.918, \mathrm{CFI}=0.947$, and RMSEA $=0.039$. As shown in Figures 2 and 3 , the results show that four OSS quality variables had a positive influence on the perceived usefulness of OSS - which was also significantly associated with OSS satisfaction - in both men and women, with some variation in the strength of the paths.

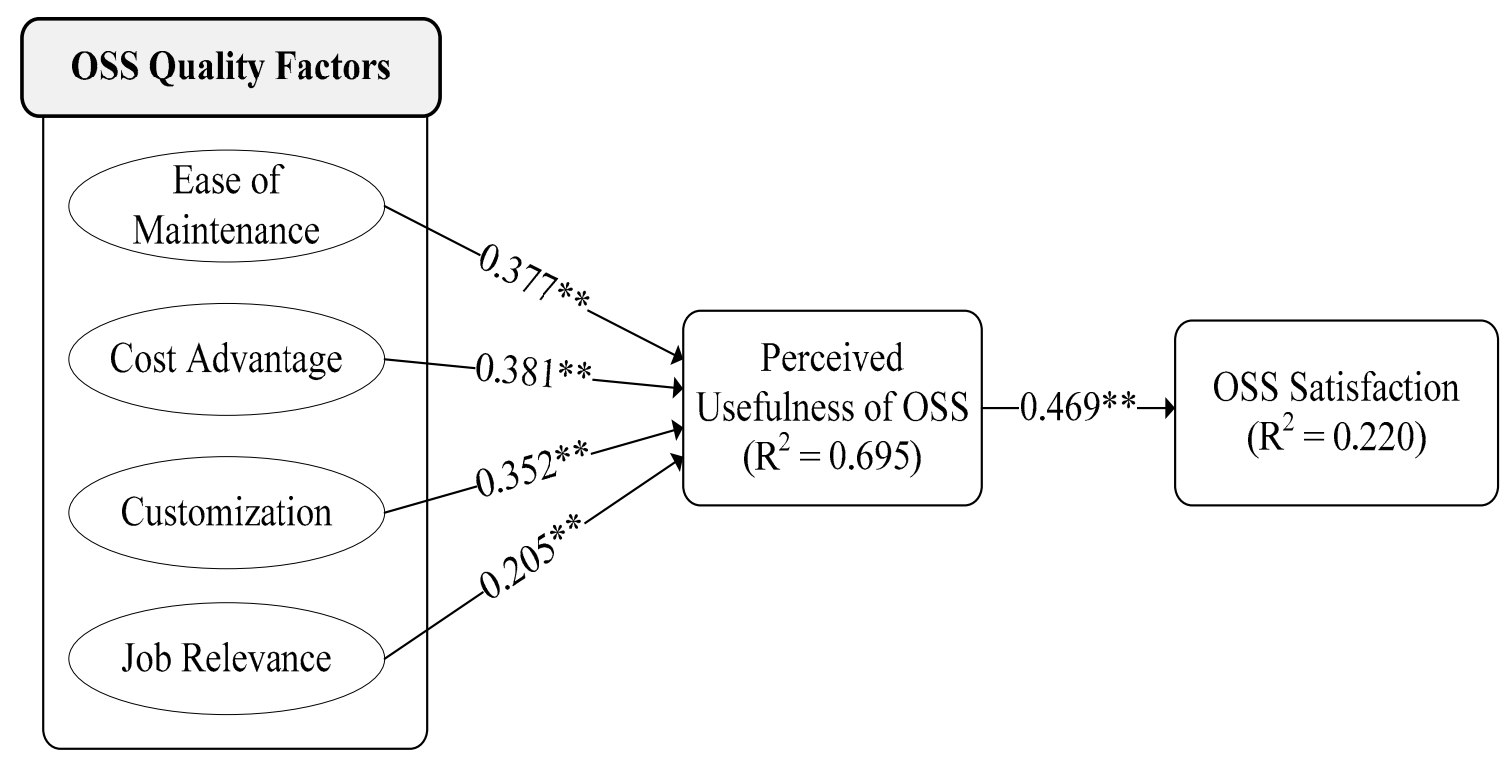

Notes: $\mathrm{X}^{2} / \mathrm{df}=1.790, \mathrm{NFI}=0.944, \mathrm{GFI}=0.961, \mathrm{AGFI}=0.925, \mathrm{CFI}=0.953, \mathrm{RMSEA}=0.036$, $* *: \mathrm{p}<0.01$

Figure 2. The structural model for males $(n=176)$.

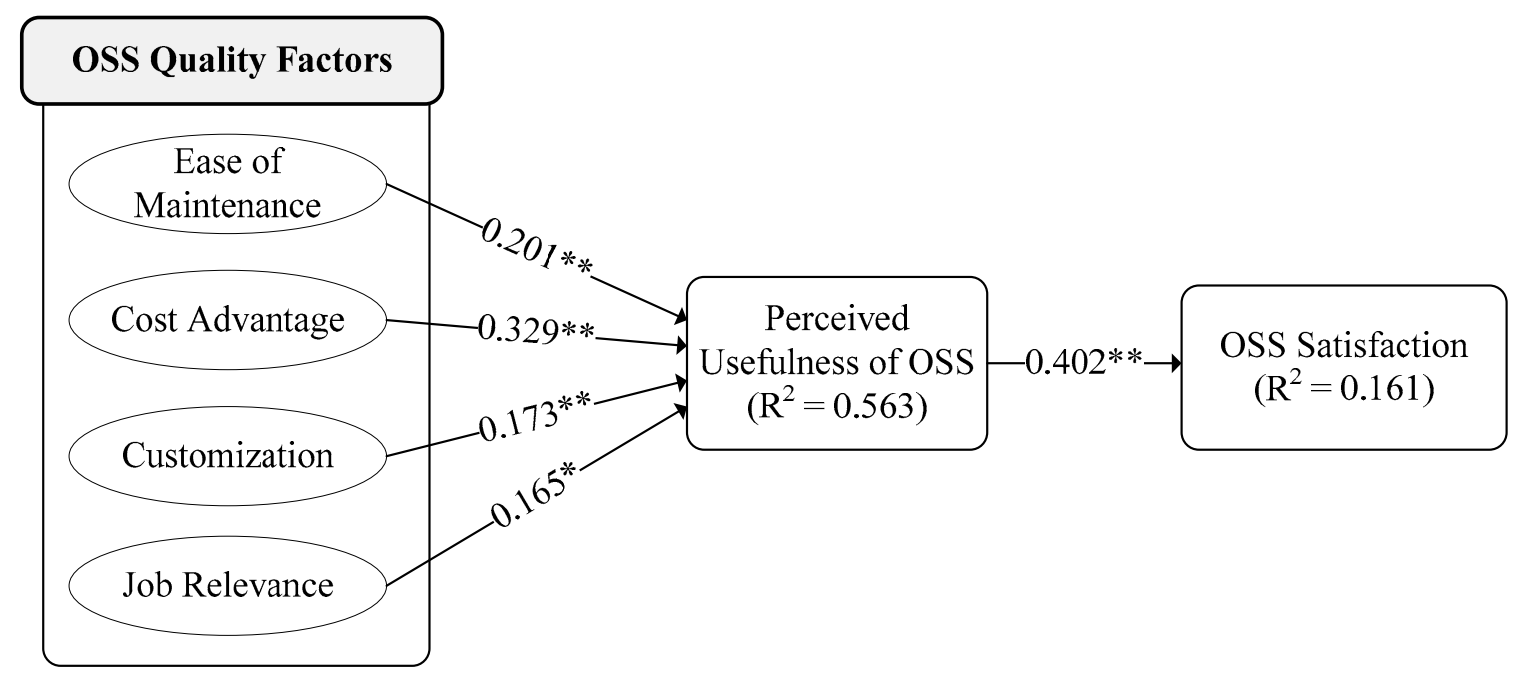

Notes: $\mathrm{X}^{2} / \mathrm{df}=1.820, \mathrm{NFI}=0.929, \mathrm{GFI}=0.965, \mathrm{AGFI}=0.918, \mathrm{CFI}=0.947, \mathrm{RMSEA}=0.039$, $*: \mathrm{p}<0.05, * *: \mathrm{p}<0.01$

Figure 3. The structural model for females $(n=152)$.

The standardized path coefficient between ease of maintenance and the perceived usefulness of OSS was 0.377 for men and 0.201 for women, which was significant at $p<0.01$. Therefore, H1 is supported. This result indicates that both male and female employees (and firms) want to use software that can be easily maintained and given specific needs, duties, and responsibilities. 
Since it is unlikely that software management would be a priority for such employees, the management of software used for their jobs needs to be easy. This supports the claims of previous studies (e.g., Sarrab and Rehman 2014) that employees tend to perceive technology as more useful when it is easy to use.

Moreover, cost advantage and customization among men resulted in standardized path coefficients of 0.381 and 0.352 , respectively, and 0.329 and 0.173 among women, respectively. Thus, $\mathrm{H} 2$ and $\mathrm{H} 3$ were supported at $p<0.01$. Cost advantage for both male and female employees was shown to have the greatest impact on users' perception of the usefulness of OSS because most users appreciate the usefulness of OSS as free software. In this respect, Lundell et al. (2010) have argued that, because of the limited resources of many organizations, the cost advantage of OSS alone makes managers aware of its usefulness. Furthermore, since OSS source code is free, organizations can customize software by modifying the source code to suit their needs. Indeed, where commercial software is difficult to customize, OSS can be customized to suit an organization's business processes or environment, increasing its perceived usefulness.

Job relevance was significantly related to the perceived usefulness of OSS, with a path coefficient of 0.205 for men and 0.165 for women. Therefore, H4 was supported for both men and women. This result indicates that some users were highly aware of the usefulness of OSS because of its relevance to their work. This supports the argument of Mount and Fernandes (2013) that the more job-related software is, the greater its perceived usefulness.

Finally, the relationship between perceived usefulness and OSS satisfaction was significant for both men and women, with a path coefficient of 0.469 for men and of 0.402 for women. Thus, $\mathrm{H} 5$ was supported at $p<0.01$. This result indicates that users' levels of satisfaction increase when they consider OSS to be useful, and is consistent with the results of previous studies (e.g., DeLone and McLean 2003; Sarrab and Rehman 2014). Figures 2 and 3 illustrate the results of the structural model for both genders, while Tables 7 and 8 summarize the results of the hypothesis tests.

Table 7. Summary of hypothesis tests (Male group, $n=176$ ).

\begin{tabular}{ccccccc}
\hline Hypothesis & & Path & Std. $\boldsymbol{\beta}$ & $\boldsymbol{t}$-Value & Result \\
\hline H1 & Ease of Maintenance & & & 0.377 & 5.734 & $\mathrm{~S}^{* *}$ \\
$\mathrm{H} 2$ & Cost Advantage & $\rightarrow$ & Perceived Usefulness of OSS & 0.381 & 7.650 & $\mathrm{~S}^{* *}$ \\
$\mathrm{H} 3$ & Customization & & & 0.352 & 5.231 & $\mathrm{~S}^{* *}$ \\
$\mathrm{H} 4$ & Job Relevance & & & 0.205 & 3.885 & $\mathrm{~S}^{* *}$ \\
\hline $\mathrm{H} 5$ & Perceived Usefulness of OSS & $\rightarrow$ & OSS Satisfaction & 0.469 & 8.463 & $\mathrm{~S}^{* *}$ \\
\hline
\end{tabular}

Note: ${ }^{* *}: p<0.01 ; \mathrm{S}:$ Supported.

Table 8. Summary of hypothesis tests (Female group, $n=152$ ).

\begin{tabular}{|c|c|c|c|c|c|c|}
\hline Hypothesis & & Path & & Std. $\beta$ & $t$-Value & Result \\
\hline $\mathrm{H} 1$ & Ease of Maintenance & \multirow{4}{*}{$\rightarrow$} & \multirow{4}{*}{ Perceived Usefulness of OSS } & 0.201 & 3.992 & $S * *$ \\
\hline $\mathrm{H} 2$ & Cost Advantage & & & 0.329 & 5.554 & $S * *$ \\
\hline H3 & Customization & & & 0.173 & 3.075 & $S^{* *}$ \\
\hline $\mathrm{H} 4$ & Job Relevance & & & 0.165 & 2.214 & $S^{*}$ \\
\hline H5 & Perceived Usefulness of OSS & $\rightarrow$ & OSS Satisfaction & 0.402 & 6.095 & $S^{* *}$ \\
\hline
\end{tabular}

Regarding the $R^{2}$ for men, four external constructs-ease of maintenance, cost advantage, customization, and job relevance-explained $69.5 \%$ of the variance in the perceived usefulness of OSS, thus explaining $22.0 \%$ of the variance in OSS satisfaction. This means that $69.5 \%$ of the information contained by the endogenous variable — that is, the perceived usefulness of OSS — was determined by the direction in which the four exogenous variables moved. Similarly, $22.0 \%$ of the information 
contained by the variable of OSS satisfaction moved in the same direction as the perceived usefulness of OSS. Among women, these four OSS quality factors explained $56.3 \%$ of the variance in the perceived usefulness of OSS, thus explaining $16.1 \%$ of the variance in OSS satisfaction.

After evaluating the direct effects among both the men and the women, a multi-group moderation analysis was performed to determine whether gender had an effect on the path relationships in the primary research model. Based on the model developed by Keil et al. (2000), $t$-value differences were calculated for each pair of gender groups (i.e., male and female) on the main paths, the results of which are provided in Table 9. The moderation effect of gender on the path between ease of maintenance and perceived usefulness of OSS was significant, indicating that the importance of ease of maintenance-which affects OSS usefulness-is valued more by male employees than it is by female employees. The results also show differences between male and female employees in other paths: customization $\rightarrow$ perceived usefulness of OSS, and job relevance $\rightarrow$ perceived usefulness of OSS). There were no differences in two paths: cost advantage $\rightarrow$ perceived usefulness of OSS, and perceived usefulness of OSS $\rightarrow$ OSS satisfaction.

Table 9. Path differences between male and female employees.

\begin{tabular}{ccccccc}
\hline Gender & Path & Std. $\beta$ & SE & $t$-Value & \multicolumn{2}{c}{ Gender Differences } \\
\cline { 5 - 7 } & & & & & $\begin{array}{c}t \text {-Value } \\
(p \text {-Value })\end{array}$ & Result \\
\hline Male & Ease of Maintenance $\rightarrow$ & $0.377^{* *}$ & 0.069 & 5.734 & $2.015^{*}$ & Different \\
Female & Perceived Usefulness of OSS & $0.201^{* *}$ & 0.050 & 3.992 & $(0.022)$ & \\
\hline Male & Cost Advantage $\rightarrow$ & $0.381^{* *}$ & 0.097 & 7.650 & 0.370 & Not \\
Female & Perceived Usefulness of OSS & $0.329^{* *}$ & 0.102 & 5.554 & $(0.356)$ & Different \\
\hline Male & Customization $\rightarrow$ & $0.352^{* *}$ & 0.085 & 5.231 & $1.668^{*}$ & Different \\
Female & Perceived Usefulness of OSS & $0.173^{* *}$ & 0.061 & 3.075 & $(0.050)$ & \\
\hline Male & Job Relevance $\rightarrow$ & $0.205^{* *}$ & 0.019 & 3.885 & $1.843^{*}$ & Different \\
Female & Perceived Usefulness of OSS & $0.165^{*}$ & 0.011 & 2.214 & $(0.033)$ & \\
\hline Male & Perceived Usefulness of OSS & $0.469^{* *}$ & 0.055 & 8.463 & 1.027 & Not \\
Female & $\rightarrow$ OSS Satisfaction & $0.402^{* *}$ & 0.030 & 6.095 & $(0.153)$ & Different \\
\hline
\end{tabular}

Note: ${ }^{*}: p<0.05,{ }^{* *}: p<0.01$.

\section{Conclusions}

This study examined OSS quality factors affecting the perceived usefulness of and satisfaction with OSS among employees currently using OSS as a primary information technology strategy. On the basis of the literature, this study proposed four OSS quality factors: (1) ease of maintenance, (2) cost advantage, (3) customization, and (4) job relevance. These factors influence the perceived usefulness of OSS and, thus, positively affect OSS satisfaction. A total of 328 questionnaire responses $($ males $=176$, females $=152)$ were collected from employees of SMEs in various industries and analysed to test the proposed hypotheses. The results of the analysis show that the measurement model was satisfactory in terms of its overall fit, reliability, and validity (see Tables 3-6). The results of the structural model also support the five hypotheses proposed in this study for both genders (see Tables 7 and 8).

The results of this study can be summarized in three points. First, ease of maintenance, cost advantage, customization, and job relevance positively influenced the perceived usefulness of OSS. These results were consistent with those of previous studies (e.g., Kim 2008; Sarrab and Rehman 2014; Zeithaml et al. 2002) on user behavior regarding a particular technology. Employees were shown to have more a positive perception of and higher satisfaction levels with OSS when it is easy to maintain and customize, provides cost benefits, and is relevant to their jobs. Second, employees in various industries believed that a positive perception of usefulness increased their expectation regarding 
OSS satisfaction. This result was also consistent with previous studies (e.g., Bhattacherjee 2001; Wang and Song 2017). Third, the responses of male employees had a greater effect on perceived usefulness of OSS than those of female employees in all four OSS quality variables, as well as in the impact of perceived usefulness of OSS on OSS satisfaction. These results suggest that male employees are more likely to consider the features and advantages of a technology when using certain information technologies such as OSS. Among the four OSS quality factors, cost advantage was found to have the greatest influence on the perceived usefulness of OSS among both male and female employees. This is unsurprising insofar as OSS is considered to have a significant cost advantage and many users are aware of the usefulness of OSS in this respect. The second most significant factor affecting the perceived usefulness of OSS was ease of maintenance, followed by customization and job relevance.

With regard to gender, the findings of this study indicate that the relationships between OSS quality factors, as well as the perceived usefulness of and satisfaction with OSS, may differ according to gender in SMEs. Based on configuration theory used in organizational research, studies have demonstrated that congruence influences an organization's use of information technology (Meyer et al. 1993). Congruence indicates that the true value of a specific technology can be determined by investigating the actual users and grouping the capabilities of a particular information technology according to user "demographics" (Fink 2011). In this study, gender was used as a demographic value to group respondents. There was a significant difference in three paths through which male and female employees perceived the usefulness of OSS: ease of maintenance $\rightarrow$ perceived usefulness of OSS, customization $\rightarrow$ perceived usefulness of OSS, and job relevance $\rightarrow$ perceived usefulness of OSS.

However, there was no difference according to gender in two paths: cost advantage $\rightarrow$ perceived usefulness of OSS, and perceived usefulness of OSS $\rightarrow$ OSS satisfaction. These results suggest that the relationship between the cost advantage and usefulness of OSS perceived by male employees is similar to the relationship between the cost advantage and usability of OSS perceived by female employees. In other words, cost advantage is recognized as being significant in OSS usefulness by both male and female employees. A similar interpretation appears in regard to the perceived usefulness of and satisfaction with OSS: both male and female employees are satisfied with OSS if they recognize the usefulness of OSS.

The results of this study have diverse academic and practical implications. First, it is significant that OSS quality factors that affect the perceived usefulness of and satisfaction with OSS technology can be identified from an organizational perspective and empirically tested. This is likely to facilitate future studies that seek to explain the behavior of individuals and organizations, particularly SMEs. Furthermore, this study has practical value in that it employed a theoretical research model developed on the basis of interviews conducted with corporate users to investigate OSS satisfaction. Second, while there has been a great deal of theoretical support for OSS quality factors being linked to gender differences that can explain the usefulness of and satisfaction with OSS, there is a notable lack of empirical support in this area. Addressing this gap, this study contributes to information systems literature in relation to gender by developing items for measuring OSS quality constructs and validating these items in the context of OSS. Although gender issues have been addressed in several social science studies, particularly those related to information systems, this study is the first to investigate user OSS perceptions in the SME environment according to gender. In this respect, the results of this study reaffirm the importance of gender in information systems research by providing specific information on differences in the perceived behavior of OSS users according to gender.

Practically, the findings of this study will be of interest to companies using OSS, providing information on what to focus on in helping users recognize the usefulness of OSS and derive satisfaction accordingly. More specifically, ease of maintenance and customization were identified as particularly important factors for OSS users in perceiving the technology's usefulness, regardless of gender. Therefore, companies using OSS should provide users with a variety of support in order to enhance OSS ease of maintenance. In addition, OSS service providers can be more informed when exploring the professions or business areas that require OSS, thus enhancing their 
ability to target OSS use more precisely through intensive marketing activities and by developing services that OSS users require and to which they respond well. Another contribution of this study concerns the strategic use of available information systems resources. Given this study's finding that the perceived usefulness of OSS varies according to gender, SMEs may find it beneficial to use different strategies for OSS use depending on the gender of their employees. The findings of this study also underscore the usefulness of OSS for companies that want to adapt to rapidly changing business environments and developing information technology, as well as to improve their competitive advantage, reduce their costs, and increase work efficiency. Finally, this study shows that OSS is used in many SMEs regardless of industry type. As such, the results of this study indicate that companies using OSS need to develop various services in order to continue to grow and maintain their place within the world of information systems technology.

This study has some limitations that need to be addressed in future studies. First, the study focused on OSS quality factors only, limiting the range of potentially influential factors. There may be a variety of external factors that influence user perceptions of the usefulness of OSS to varying degrees. Therefore, future studies should investigate other external factors that may affect user perceptions of OSS and subsequent satisfaction. With regard to the measurement of some items, particularly cost advantage, this study did not include items measuring the quantitative aspect, such as total cost of ownership. Thus, future studies should include both quantitative and qualitative items to measure latent variables. Moreover, since this study was conducted at a specific point in time, it was unable to identify to what extent user perceptions regarding the usefulness of and their satisfaction with OSS may have changed over time. As such, future research should examine the behavior of OSS users over time in order to further test the findings of this study.

Author Contributions: As the main contributor, S.K. outlined and collected the data, conducted the first round of analysis, and performed the literature review. H.P. reorganized the manuscript; conducted an additional literature review; conceptualized the work, research design, and discussion; and completed a reference check.

Funding: This research was supported by Kyungpook National University Bokhyeon Research Fund, 2015.

Conflicts of Interest: The authors declare no conflict of interest.

\section{Appendix A. Survey Questionnaires}

\begin{tabular}{ll}
\hline Variable & \\
\hline $\begin{array}{l}\text { Ease of Maintenance } \\
\text { em1: }\end{array}$ & Learning to operate OSS would be easy for me. \\
em2: & I would find OSS easy to maintain. \\
em3: & My interaction with OSS is clear and understandable. \\
em4: & I would find updating and solving problems with OSS very simple. (Removed.) \\
\hline $\begin{array}{l}\text { Cost Advantage } \\
\text { ca1: }\end{array}$ & In my job, usage of OSS saves costs related to time and effort. \\
ca2: & In my job, I can avoid unnecessary costs by using OSS. \\
ca3: & OSS is more cost effective than other technologies. \\
ca4: & OSS does not incur additional tangible and intangible costs after implementation. \\
\hline Customization & \\
cus1: & With OSS, I can get customized interfacing of the information systems I use. \\
cus2: & OSS gives me a high level of flexibility in the use of information technology, \\
cus3: & enabling me to build new systems and customized systems in the future. \\
cus4: & I can customize the system that I use daily without any issues. (Removed.) \\
\hline
\end{tabular}




\begin{tabular}{ll}
\hline Variable & \\
\hline $\begin{array}{l}\text { Job Relevance } \\
\text { jr1: }\end{array}$ & In my job, use of OSS is high. \\
jr2: & In my job, usage of OSS is relevant. \\
jr3: & OSS is highly related to my daily tasks. \\
\hline Perceived Usefulness & \\
pu1: & Using OSS would improve my job performance. \\
pu2: & Using OSS in my job would enable me to accomplish tasks more quickly. \\
pu3: & Using OSS would enhance my effectiveness on the job. \\
pu4: & Using OSS in my job would increase my productivity. \\
\hline OSS Satisfaction & \\
sat2: & I am more satisfied with OSS than with other commercial software. \\
sat2: & I am satisfied with OSS in terms of job performance. \\
\hline
\end{tabular}

\section{References}

An, Dae-Chun, and Sang-Hoon Kim. 2011. Factors Influencing Mobile Commerce Adoption in Korea: The Gender Gap. Advertising Research 88: 7-36.

Bailey, James E., and Sammy W. Pearson. 1983. Development of a Tool of Measuring and Analyzing Computer User Satisfaction. Management Science 29: 530-44. [CrossRef]

Bhattacherjee, Anol. 2001. Understanding Information Systems Continuance: An Expectation-Confirmation Model. MIS Quarterly 25: 351-70. [CrossRef]

Chauhan, Sumedha, Mahadeo Jaiswal, Sumita Rai, Luvai Motiwalla, and Leo Pipino. 2018. Determinants of Adoption for Open-Source Office Applications: A Plural Investigation. Information Systems Management 35: 80-97. [CrossRef]

Chiasson, Mike W., and Chris Y. Lovato. 2001. Factors Influencing the Formation of a User's Perceptions and Use of a DSS Software Innovation. DATABASE for Advances in Information Systems 32: 16-35. [CrossRef]

Cho, Hwi-Hyung. 2012. Study on Influence of Perceived Quality Factor of Smartphone on Satisfaction and Continued Use Intention: From the Standpoint of Updated Delone \& McLean's Information System Success Model. Entrue Journal of Information Technology 11: 167-80.

Chin, Wynne W. 1998. The Partial Least Squares Approach for Structural Equation Modeling. In Modern Methods for Business Research. Edited by George A. Marcoulides. Hillsdale: Lawrence Erlbaum, pp. 295-336. ISBN 9780805830934.

Davis, Fred D. 1989. Perceived Usefulness, Perceived Ease of Use, and User Acceptance of Information Technology. MIS Quarterly 13: 319-40. [CrossRef]

DeLone, William H., and Ephraim R. McLean. 2003. The DeLone and McLean Model of Information Systems Success: A Ten-Year Update. Journal of Management Information Systems 19: 9-30. [CrossRef]

Dishaw, Mark T., and Diane M. Strong. 1999. Extending the Technology Acceptance Model with Task Technology Fit Constructs. Information and Management 36: 9-21. [CrossRef]

Fink, Lior. 2011. How do IT capabilities create strategic value? Toward greater integration of insights from reductionistic and holistic approaches. European Journal of Information Systems 20: 16-33. [CrossRef]

Gallego, M. Dolores, Paula Luna, and Salvador Bueno. 2008. User Acceptance Model of Open Source Software. Computers in Human Behavior 24: 2199-216. [CrossRef]

Gwebu, Kholekile L., and Jing Wang. 2011. Adoption of Open Source Software: The Role of Social Identification. Decision Support Systems 51: 220-29. [CrossRef]

Jusoh, Yusmadi, Khadijah Chamili, Jamaiah H. Yahaya, and Noraini Che Pa. 2012. The Selection Criteria of Open Source Software Adoption in Malaysia. International Journal of Advancements in Computing Technology 42: 278-87. [CrossRef]

Kim, Sang Hyun. 2008. Moderating Effects of Job Relevance and Experience on Mobile Wireless Technology Acceptance: Adoption of a Smartphone by Individuals. Information \& Management 45: 387-93. [CrossRef]

Kim, Sang Hyun, and Young Mi Song. 2010. An Empirical Study of Factors Influencing Diffusion of Open Source Software and the Moderating Effect of Government Supports. Information Systems Review 12: 89-116. 
Lundell, Björn, Brian Lings, and Edvin Lindqvist. 2010. Open Source in Swedish Companies: Where are We? Information Systems Journal 20: 519-35. [CrossRef]

Marsan, Josianne, Guy Paré, and Anne Beaudry. 2012. Adoption of Open Software in Organizations: A Socio-Cognitive Perspective. The Journal of Strategic Information Systems 21: 257-73. [CrossRef]

McCreadie, Maureen, and Ronald E. Rice. 1999. Trends in Analyzing Access to Information. Part I: Cross-Disciplinary Conceptualizations of Access. Information Processing \& Management 35: 45-76. [CrossRef]

Meyer, Alan D., Anne S. Tsui, and C. Robert Hinings. 1993. Configurational Approaches to Organizational Analysis. Academy of Management Journal 36: 1175-95. [CrossRef]

Midha, Vishal, and Prashant Palvia. 2012. Factors Affecting the Success of Open Source Software. Journal of Systems and Software 85: 895-905. [CrossRef]

Mount, Matthew Paul, and Kiran Fernandes. 2013. Adoption of Free and Open Source Software within High-Velocity Firms. Behaviour \& Information Technology 32: 231-46. [CrossRef]

Nagy, Del, Areej M. Yassin, and Anol Bhattacherjee. 2010. Organizational Adoption of Open Source Software: Barriers and Remedies. Communications of the ACM 53: 148-51. [CrossRef]

Ong, Chorng-Shyong, and Jung-Yu Lai. 2006. Gender Differences in Perceptions and Relationships among Dominants of E-Learning Acceptance. Computers in Human Behavior 22: 816-29. [CrossRef]

Keil, Mark, Bernard Tan, Kwok-Kee Wei, Timo Saarinen, Virpi Tuunainen, and Arjen Wassenaar. 2000. A Cross-Cultural Study on Escalation of Commitment Behavior in Software Projects. MISQ 24, 299-325. [CrossRef]

Park, Cheol-Woo, and Hae-Joo Jeong. 2012. An Empirical Study on the Effects of Personal and Systematic Characteristics on the Acceptance of Technologically Innovative Products-With Focus on Cloud Computing. Asia Pacific Journal of Business Venturing and Entrepreneurship 7: 63-76. [CrossRef]

Rhee, Young-Ju. 2010. The Effects of e-CRM on Consumer Satisfaction and Repurchase Intention. Journal of the Korean Society of Clothing and Textiles 34: 1277-89. [CrossRef]

Rice, Ronald E., and James E. Katz. 2003. Comparing Internet and Mobile Phone Usage: Digital Divides of Usage, Adoption, and Dropouts. Telecommunications Policy 27: 597-623. [CrossRef]

Roger, Everett M. 1995. Diffusion of Innovations, 5th ed. New York: Free Press.

Sarrab, Mohamed, and Osama M. Hussain Rehman. 2014. Empirical Study of Open Source Software Selection for Adoption, Based on Software Quality Characteristics. Advanced in Engineering Software 69: 1-11. [CrossRef]

Seddon, Peter B. 1997. A Respecification and Extension of the Delone and Mclean Model of IS Success. Information Systems Research 8: 240-53. [CrossRef]

Seddon, Peter B., and Min-Yen Kiew. 1996. A Partial Test and Development of Delone and Macleans' Model of IS Success. Australian Journal of Information Systems 4: 90-109. [CrossRef]

Seddon, Peter B., Sandy Staples, Ravi Patnayakuni, and Matthew Bowtell. 1999. Dimensions of Information Systems Success. Communications of the Association for Information System 2: 2-61.

Son, Jai Yeol, Sridhar Narasimhan, and Frederick J. Riggins. 2005. Effects of Relational Factors and Channel Climate on EDI Usage in the Customer Supplier Relationship. Journal of Management Information System 22: 321-53. [CrossRef]

Teo, Thompson S. H., Vivien K. G. Lim, and Raye Y. C. Lai. 1999. Intrinsic and Extrinsic Motivation in Internet Usage. Omega 27: 25-37. [CrossRef]

Van Loon, Alexander, and Dimiter Toshkov. 2015. Adopting Open Source Software in Public Administration: The Importance of Boundary Spanners and Political Commitment. Government Information Quarterly 32: 207-15. [CrossRef]

Van Riel, Allard C. R., Jos Lemmink, and Sandra Streukens. 2004. Boost Customer Loyalty with Online Support: The Case of Mobile Telecoms Providers. International Journal of Internet Marketing and Advertising 1: 4-23. [CrossRef]

Ven, Kris, and Jan Verelst. 2011. An Empirical Investigation into the Assimilation of Open Source Server Software. Communications of the Association for Information Systems 28: 117-40.

Venkatesh, Viswaqnath, and Fred D. Davis. 2000. A Theoretical Extension of the Technology Acceptance Model: Four Longitudinal Field Studies. Management Science 46: 186-204. [CrossRef] 
Wang, Guangbin, and Jiule Song. 2017. The Relation of Perceived Benefits and Organizational Supports to User Satisfaction with Building Information Model (BIM). Computers in Human Behavior 68: 493-500. [CrossRef] Zeithaml, Valarie A., A. Parasurman, and Arvind Malhotta. 2002. Service Quality Delivery through Web Sites: A Critical Review of Extant Knowledge. Journal of Academy of Marketing Science 30: 362-75. [CrossRef] 